\title{
Commentary: Will the circle be unbroken?
}

\author{
Alan M. Speir, MD \\ From the Department of Cardiac Surgery, Inova Heart and Vascular Institute, Falls Church, Va. \\ Disclosures: Author serves on the Medtronic Cardiac Surgery Advisory Board and the Atricure Advisory Board. \\ Received for publication July 31, 2019; accepted for publication Aug 1, 2019; available ahead of print Sept 27, \\ 2019. \\ Address for reprints: Alan M. Speir, MD, Department of Cardiac Surgery, Inova Heart and Vascular Institute, 3300 \\ Gallows Rd, Falls Church, VA 22042 (E-mail: alan.speir@inova.org). \\ J Thorac Cardiovasc Surg 2020;159:2168-9 \\ 0022-5223/\$36.00 \\ Copyright $(2019$ by The American Association for Thoracic Surgery \\ https://doi.org/10.1016/j.jtcvs.2019.08.013
}

In the hymn "Will the Circle Be Unbroken," written in 1907 by Ada R. Habershon, ${ }^{1}$ the central tenet is that the legacy, knowledge, and lessons learned by those who have gone before us will be passed to those left behind. Such data transfer has enabled those who remain to maintain a connection, a circle, with those who have died, not to mention that the hymn has remained a go-to ritual everywhere from worship services to family memorials, gospel sings, bluegrass picking parties, Americana award show finales, and the annual Country Music Hall of Fame induction ceremony. Such a circle of stability and connectivity can be demonstrated anatomically as well, with even greater implications. Thomas Willis (1621-1675), considered one of the greatest neuroanatomists of all time, wrote Cerebri Anatome (Cerebri Anatome Neroorumgue Descriptio el Usus-The Anatomy of the Brain and Nerves) in 1664 while Professor of Natural Philosophy at Oxford. This work included Willis's classification of the cranial nerves and his description of the arterial pattern at the base of the brain widely known as the circle of Willis. ${ }^{2}$

The circle of Willis, an arterial ring at the base of the brain in the interpeduncular fossa, is formed by the anastomosis between the 2 internal carotid arteries and the 2 vertebral arteries, with contributions from the anterior communicating, anterior cerebral, internal carotid, posterior communicating, posterior cerebral, and basilar arteries. Cerebral cross-perfusion through an intact arterial arcade is thought to be essential for ipsilateral brain viability, particularly during unilateral cerebral insult or cardiac surgical procedures that rely on such arterial relationships during antegrade cerebral perfusion for complex thoracic aortic reconstruction. Questions regarding perfusion strategies for cerebral preservation, specifically unilateral or bilateral antegrade cerebral perfusion, become more vexing given the known incompleteness and variability of the circle of Willis in $17 \%$ to $40 \%$ of brains examined by anatomic or angiographic studies. ${ }^{3-5}$

The article by Angleitner and colleagues ${ }^{6}$ published in this month's Journal represents another publication that

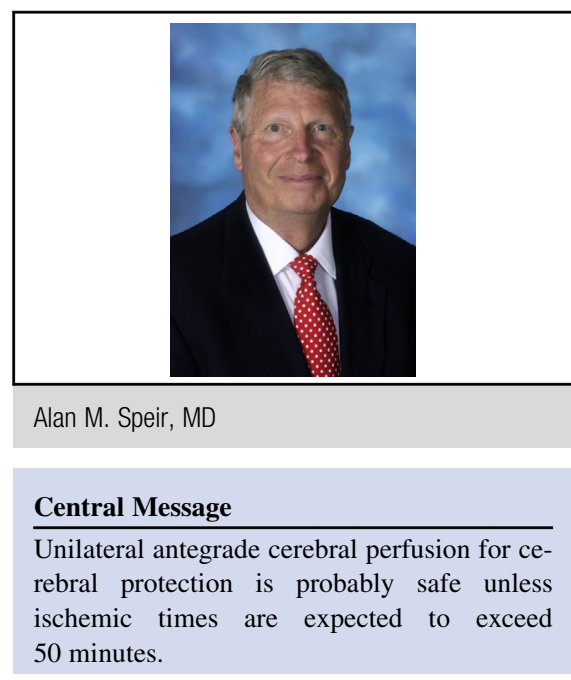

See Article page 2159.

seeks to address the fundamental issue of appropriate cerebral protection by unilateral or bilateral cerebral perfusion during cardiac surgical repair of acute type A aortic dissection. Although the results of this single-center analysis are significantly limited by the small sample size and the expertise of an experienced aortic team operating on only $31.5 \%$ of cases, the results conclude that bilateral antegrade cerebral perfusion "is associated with significantly improved overall survival in patients requiring antegrade cerebral perfusion durations $\geq 50$ min." 6 Their results support the findings of improved mortality rates in literature reviews ${ }^{7}$ and meta-analyses in patients treated with bilateral antegrade perfusion when circulatory arrest times are longer than 30 to 40 minutes. $^{8}$ Such strategy is incomplete, however, unless moderate hypothermia $\left(24^{\circ} \mathrm{C}-28^{\circ} \mathrm{C}\right)$ is used, perfusion flows are maintained at 6 to $10 \mathrm{~mL} / \mathrm{kg} / \mathrm{min}$ with pressures of 40 to $60 \mathrm{~mm} \mathrm{Hg},{ }^{7}$ and monitoring of regional cerebral oxygen saturation with near-infrared spectroscopy is considered. ${ }^{9}$

Until adequately powered, prospective, randomized, controlled trials are performed to address this issue more accurately, it remains to be seen whether the "circle" can be "broken" or incomplete, and perfused only unilaterally without deleterious results in mortality and morbidity. Judicious use of unilateral antegrade cerebral perfusion with a permissive and aggressive default to bilateral perfusion with the expectation of longer cardiac arrest times, or if there are declines in regional cerebral 
oxygen saturation, may allow more consistent clinical results.

\section{References}

1. Habershon AR, Gabriel CH. Will the circle be unbroken? In: Alexander CM, ed. Alexander's Gospel Songs No. 2. New York: Fleming H Revell Company; 1907:33.

2. Üstün C. Dr Thomas Willis' famous eponym: the circle of Willis. Turk J Med Sci. 2004;34:271-4.

3. Urbanski PP, Lenos A, Blume JC, Ziegler V, Griewing B, Schmitt R, et al. Does anatomical completeness of the Circle of Willis correlate with sufficient crossperfusion during unilateral cerebral perfusion? Eur J Cardiothorac Surg. 2008; 33:402-8.

4. Macci C, Catini C, Federico C, Gulisano M, Pacini P, Cecchi F, et al. Magnetic resonance angiographic evaluation of circulus arteriosus cerebri (circle of Willis): a morphologic study in 100 human healthy subjects. It J Anat Embryol. 1996;101: 115-23.

5. Merkkola P, Tulla H, Ronkainen A, Soppi V, Oksala A, Kovisto T, et al. Incomplete circle of Willis and right axillary artery perfusion. Ann Thorac Surg. 2006;82:74-9.

6. Angleitner P, Stelzmueller ME, Mahr S, Kaider A, Laufer G, Ehrlich M. Bilateral or unilateral antegrade cerebral perfusion during surgery for acute type A dissection. J Thorac Cardiovasc Surg. 2020;159:2159-67.e2.

7. Spielvogel D, Kai M, Tang G, Malekan R, Lansman S. Selective cerebral perfusion: a review of the evidence. J Thorac Cardiovasc Surg. 2013;145(3 Suppl): S59-62.

8. Angeloni E, Melina G, Refice S, Roscitano A, Capuano F, Comito C, et al. Unilateral versus bilateral antegrade cerebral protection during aortic surgery: an updated meta-analysis. Ann Thorac Surg. 2015;99:2024-31.

9. Lewis C, Parulkar S, Bebawy J, Sherwani S, Hogue C. Cerebral neuromonitoring during cardiac surgery: a critical appraisal with an emphasis on near-infrared spectroscopy. J Cardiothorac Vasc Anesth. 2018;32:2313-22. 